\title{
FITOGEOMORFOLOGIA E ANÁLISE AMBIENTAL
}

\author{
Everton PASSOS \\ Professor Adjunto do Departamento de Geografia - UFPR \\ Geógrafo \\ Mestre em. Solos \\ Doutorando em Engenharia Florestal
}

\begin{abstract}
The combination study of landforms and plantforest cover (natural vegetation or whit antropic alteration) is termed "Phitogeomorphology", and this provide a powerful interpretation aid, for evironmental analyses. This is more useful, when we want to understand the landscape dynamics. In the context of this paper, only the briefst of coments can be made on phytogeomorphology, and show some relations of vegetation distribuition and morphology of the landscape and theirs processes (geomorphology), that provide from the interaction of these with the climate that result in the principals components of landforms and their dynamics evolution. In vegetation cover their influences is seen by changes in site quality, in the physiognomy of the natural cover, by abrupt variations in the vegetation cover, and /or by the distribuition of indicater especies. dynamics.

KEY WORDS: Phitogeomorphology, evironmental analyses, landscape

RESUMO

O estudo combinado das formas do relevo e a cobertura vegetal / florestal (vegetação natural ou alterada pela açăo antrópica) denominado "fitogeomorfologia", fornece um poderoso recurso de interpretação na analise ambiental. Sendo bastante util quando pretende-se compreender a dinámica da paisagem. O conteúdo desse artigo é somente um breve comentário sobre a fitogeomorfologia, e mostra algumas relaçōes da distribuiçăo da vegetação e a mortologia do terreno el ou seus processos (geomorfologia), que originam-se das interaçōes destes com o clima, assumindo a posição dentre os principais componentes da fisionomia da paisagem e de sua dinámica. Na vegetação suas inluências são evidenciadas pelas mudanças na qualidade do sitio na fisionomia da cobertura vegetal, por variaçōes abruptas na cobertura el ou ainda, pela presença de bioindicadores.
\end{abstract}

PALAVRAS CHAVE:

Fitogeomorfologia, Análise Ambiental, Dinâmica da Paisagem. 


\section{INTRODUÇĀO}

Os componentes mais importantes na dinâmica da superficie da crosta terrestre emersa os processos geomorfológicos, produzem feiçōes na paisagem que caracterizam o relevo dos diferentes ambientes naturais, determinantes do tipo de cobertura vegetal, é fator esse imprescindivel ao desenvolvimento concomitante dos solos, e de toda cadeia trófica e consequeentemente base da sobrevivência dos organismos vivos e do próprio homem.

O relevo, principal constituinte fisionômico do meio físico, somado a cobertura vegetal modificada ou năo pela atividade antrópica, constituem a paisagem, a qual é um dos principais objetos da análise ambiental.

A paisagem sob o aspecto ecológico é constituida por biótopos de diferentes biocenoses, que por sua vez, compōem ecossistemas, os quais em ambientes terrestres, tem como principal componente o solo que associado ao clima constituem os mais evidentes fatores condicionantes da distribuiçăo da vegetaçāo.

O clima e os solos, portanto, são de grande importância ecológica, porém de difícil identificaçăo e delimitaçāo, tanto na observaçāo indireta em imagens de sensores remotos, (fotografias aéreas, imagens muitiespectrais, imagens de radar, etc.), quanto na observaçāo direta em campo, no entanto quando correlacionados ao relevo e a cobertura vegetal, esses podem ser mais facilmente identificados e delimitados, permitindo considerar esses últimos, como os principais fatores ambientais observáveis, cujo estudo combinado conforme, HOWARD(1991), denomina-se "Phytogeomorphology" ou fitogeomorfologia em português.

Aplicaçōes em sensoriamento-remoto demonstrando a importância do estudo fitogeomorfológico sāo destacados por: HOWARD (1970), e HOWARD; MITCHELL (1980).

Componentes marcantes das variabilidade de condiçōes ambientais terrestres, as formas de relevo estudadas pela geomorfologia e distribuiçăo da cobertura vegetal, objeto da biogeografia sâo freqūentemente utilizados em seus aspectos fitogeomorfológicos, para caracterizaçăo geográfica local e regional da paisagem, ou de seus fatores correlatos como o clima, os solos e a fitogeografia ou seja a própria composição de vegetaçằo.

A paisagem no entanto, segundo BERTRAND(1972) "... năo é a simples adição de elementos geográficos disparatados. É numa determinaçăo do espaço, - resultado da combinaçāo dinâmica, portanto instável de elementos físicos, biológicos e antrópicos que, reagindo dialeticamente uns sobre os outros, fazem da paisagem um conjunto ủnico e dissociável, em perpétua evoluçăo".

Portanto, sob o aspecto físico a paisagem na perspectiva fitogeomorfológica deve ser delineada pelas interaçōes que fazem da combinaçăo da cobertura vegetal com o relevo, não simplesmente por seu aspecto fisionômico dado à paisagem como resultante do somatório de elementos, mas principalmente como produto de processos que envolvem interaçōes entre fatores da atmostera, litosfera e biosfera ao longo do tempo geológico.

Em abordagem interdisciplinar a fitogeomorfologia, com base no conceito anteriormente apresentado para paisagem, nāo deve simplesmente fimitar-se a correlaclonar distribuiçăo de espécies e morfologia do relevo, com tipos de solos 
e clima, mas também, dedicar-se ao estudo dos diversos fatores ambientais de forma integrada, dentre os quais, a geodinâmica, a bioclimatologia, a pedologia, a biogeografia e ecologia, tanto em ambientes naturais, quanto naqueles modificados ou produzidos pelo homem. A importância da abordagem fitogeomorfoloógica, vem sendo evidenciada pela literatura a algum tempo por diversos autores, como os a seguir indicados, em breve reviāo sobre o tema ora abordado.

\section{EVIDÊNCIAS DA IMPORTÃNCIA DO ESTUDO FITOGEOMORFOLÓGICO.}

Para AB'SABER (1970), as diferentes paisagens sintetizadas em mosaicos de grandes dominios morfoclimáticos e suas "variantes endógenas", somente poderăo ser melhor compreendidas com aprofundamento de estudos fisiográficos e biogeográficos integrados.

Segundo LACOSTE; SALANON ( 1973), a açâo modificadora das formas de relevo, sobre os demais fatores ecológicos, especialmente os solos e o clima e suas consequências na distribuição da vegetaçăo, sâo determinantes na distribuiçăo biogeográfica das biocenoses. Portanto, o relevo e a vegetaçăo são objetos de destaque em estudos biogeográficos.

HACK; GOODLETT(1960), estudando a importåncia das relaçōes fitogeomorfológicas na Regiāo Central Montanhosa Apalachiana nos Estados Unidos, afirmam : "The vegetation of the Littie River area shows an extraordinarily regular distribution of forest types that is related to the similarly regular landforms. The elegance of the adjustment of vegetation, landforms and soil is a function of the geomophic processe that maintain the graded slopes." Segundo os autores a distribuiçăo e composiçăo da vegetaçäo reflete as diferenças locais em processos, vertentes (encostas) e ambiente, sendo parte de um sistema aberto, em continuo ajustamento, o que mantém tal sistema em constante evolução aọ longo do tempo geológico.

Para REMEZOV; POGAEBNYAK(1969), a distribuiçāo das formaçס̄es fiorestais e o seu desenvolvimento, săo conseqüentes da influểncia do clima (orientaçăo das encostas); no solo especialmente nas condiçōes edáficas do teor de umidade do solo (decorrentes de: orientaçăo, forma, declividade e comprimento das encostas); hidrologia ("runoff ", nivel do lençol freático), como exemplo correlacionam algumas sequências de coberturas florestais, em áreas de relevo ondulado.

Ainda, conforme REMEZOV; POGREBNYAK(1969), as caracteristicas e propriedades ecológicas (luminosidade, temperatura, umidade, nutrientes, etc.). mudam de acordo com o ambiente, e dentre os fatores ecológicos, saá particularmente importantes o relevo (fatores orográficos) e a idade (fatores históricos), na distribuiçāo das florestas. Pois, o relevo determina variaçōes na distribuiçăo espacial de fatores ambientaís como: insolaçāo, temperatura, umidade e nutrientes do solo. $\mathrm{Na}$ investigação da atual influência da topografia sobre o desenvolvimento florestal, montanhas, superficies aplainadas (planaltos e pianícies), vales, vertentes, etc., são relacionados a complexas combinações de solos, material parental, fatores climáticos, umidade, etc(fig.01). 
Fig.01- Relaçōes entre relevo e cobertura, respectivamente em áreas com vales de maior e menor amplitude. Adap. de REMEZOV; POGREBNYAK(1969).
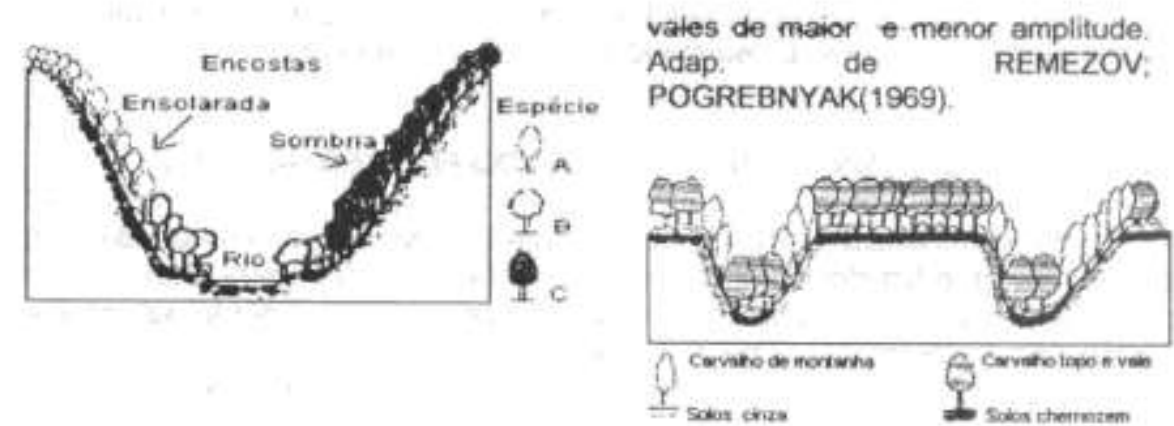

Ainda segundo os referidos autores, o pleno desenvolvimento do biótopo de uma floresta, por outro lado demanda de um relativo tempo necessário à sucessão de estágios de evolução que acompanham concomitantemente as mudanças ambientais ao longo de um periodo passado.

Segundo RIZZINI, (1979), os grandes deslocamentos no curso evolutivo tanto dos vegetais quanto animais acompanharam modificaçóes geoclimáticas (fisiográficas e paleoclimáticas), acusadas no atual panorama da natureza particularmente pelas disjunçōes e a ocorrência de espécies afins em áreas distintas,

Para o mesmo autor, a origem de algumas espécies da flora angiospérmica que compōem a biota brasileira atual, podem remontar do periodo Jurássico, fase em que as condiçôes temperado-quente ou tropical, favoreceram - desenvolvimento de muitos gêneros atuais, já que no Cretáceo a mais 100 milhōes de anos há registro de numerosos grupos atuais, desde entāo mantidos inalterados.

A participaçằo de processos da própria constituiçăo da topografia e do clima na evolução da vegetação e conseqüente distribuiçăo da flora e fauna a partir das condiçöes Cretáceo-Eoceno com alternância de fases hipotérmicas $\theta$ xerotérmicas, ou respectivamente pluviais (temperaturas mais baixas e úmido) e displuviais (aquecimento e dessecaçăo). Processos esses reconhecidos e relacionados as glaciaçōes por geólogos e geomortólogos, podem melhor explicar a atual distribuiçāo da vegetaçăo, conforme informaçōes obtidas a respeito da última glaciação Würm iniciada a 70 mil anos, e finalizada a aproximadamente 17 mil anos, produzindo movimentos da vegetaçāo que podem explicar a atual distribuiçâo vegetal na Terra.

As sucessōes paleoclimáticas e suas açōes na cobertura vegetal e conseqüências na modelagem da paisagem brasileira, (Fig.02) sāo demonstradas claramente em estudos geomorfológicos realizados no Brasil, por BIGARELLA, (1961).BIGARELLA; Ab'SABER, (1963), ANDRADE et al, (1963), BIGARELLA, (1964), BIGARELLA,et al (1975) entre outros. Relaçôes entre tipo de cobertura 
vegetal e dinåmica geomorfológica vem sendo mencionadas em inúmeros outros estudos como: BIGARELLA, (1964); DOUGLAS, (1967); SEMMEL; RHODERBURG, (1979); REMEZOV; POGREBNYAK,(1969); TRICART, (1977); De PLOEY; CRUZ, (1979); DUNNE, (1979); BROWN-Jr.; Ab'SÁBER, (1979); RHODERBURG, (1983); PICKUP; CHEWINGS (1996) entre outros.

Fig.02- Sequêcia esquemática das mudanças produzidas na fitogeomortologia durante alternâncias climáticas, adaptado de BIGARELLA; MAZUCHOWSKI(1985).

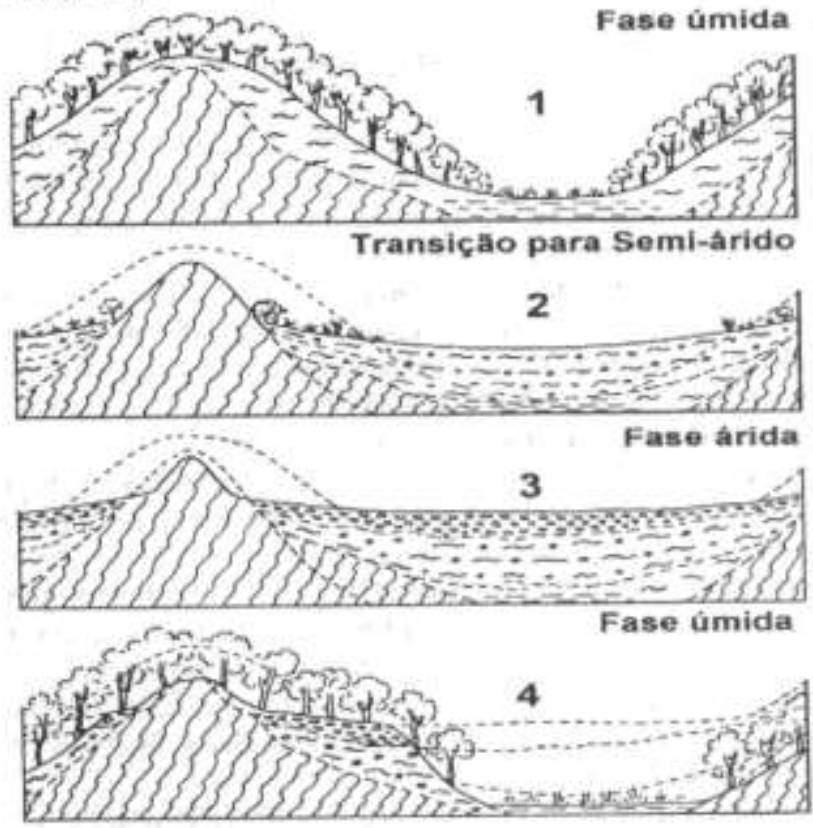

\section{EVIDÊNCIAS PALEOGEOGRÁFICAS NA ATUAL DISTRIBUIÇĀO FITO- GEOMORFOLÓGICA BRASILEIRA.}

A origem fitogeográfica da atual cobertura vegetal brasileira conforme RIZZINI, (1979), pode ser sintetizada em duas fases bem diferenciadas por condiçōes geoambientais decorrentes de mudanças climáticas a partir do Eoceno, definidas como: Fase de "formaçăo generalizada", ou fase das formaçōes primitivas; e a fase de ampia diferenciação ou diversificação, fase de diversificaçăo.

Fase das formações primitivas:

Ao analissar a preferência que a floresta atlântica, no seu melhor desenvolvimento, tem à um clima temperado-subtropical, e que juntamente com os campos limpos $\theta$ altimontanos, $\theta$ suas várias características "organográficoecológicas" conduzern a interpretaçăo de que estas biocenoses tratam-se do tipo mais primitivo na vegetação brasileira, para AIZZINI, (1979), o caráter fitoclimático "microtermófilo" dessas formaçōes vegetais é evidenciado, graças as 
semelhanças da vegetaçăo do Cabo com a formaçāo campestre central e das Florestas montana e temperada africanas, a Floresta pluvial montana brasileira, a qual observa o autor , mantém \& seu antigo caráter de "formação generalizada" sem especializaçăo eu adaptaçóes particulares.

Considerando uniformidade $\theta$ constância das condiçōes climáticas cretáceo-eocênicas (frescas e úmidas) e 0 isolamento muito prolongado do continente sul-americano, RIZZINI(1979), supobe duas formaçöes iniciais na vegetação do Brasil, uma floresta pluvial e uma vegetaçăo de campo, herbácea sobretudo ou sublenhosa, distribuidas de acordo com as condiçōes edáficas. Sendo localizadas nas partes baixas e profundas as florestas, e os campos onde o solo fosse raso e em partes elevadas como montanhas cristalinas e cristas quartziticas.

Essas formaçōes primitivas teriam deslocado as precedentes ao longo do periodo Cretáceo; indicios da preservaçäo ao longo do tempo geológica dessas formaçōes relictuais foram sugeridas por MAACK(1948) ao descrever os campos de altitude no Paraná e evidenciados por frutos fósseis do Paleoceno (aprox. 60 milhōes de anos) encontrados por BEUALEN; SOMMER em 1954. indicam pertencer a espécie Celtis brasiliensis comum na floresta atlântica, $e$ exibe frutos idênticos aos achados. Os últimos autores sugerem ainda "um clima semelhante ao de hoje na regiào" (Săo José do itaborai- Rj.). dados que segundo RIZZINI (1979), confirmam as explanaçőes anteriores a respeito do clima do Terciário, e fornecem uma idéia da constância das condiçŏes ecológicas na Serra do Mar, fator desfavorável a diversificação biológica ao contrário do que aconteceu em regiōes como a da bacia Amazónica.

As condiçōes favoráveis de "preservaçăo do caráter de generalidade da floresta attântica, e não do campo limpo, prende-se a imutabilidade de seu hábitat ... indicando menor diferenciaçāo florística", sendo que no planalto central em que o seu avanço foi bem mais recente essa apresenta significativas diferenças entre as matas derivadas como as matas secas semidesciduas, RIZZINI (1979).

Fase de diversificaçāo

No terciário superior conforme RIZZINI (1979) mais precisamente no Mioceno, periodo de atividade orogênica, as faixas climáticas eram bem diferenciadas. O Mioceno e Plioceno caracterizaram-se por menor precipitaçăo concentrada numa parte do ano, além de maior amplitude térmica; devendo mesmo no Eoceno superior ter iniciada a dessecação climática em algumas regiŏes, a qual fol marcada no Oligoceno. Na zona tropical durante o Mioceno definiu-se um periodo com estaçăo seca bem definida.

Tais fatores (orogênese elou diferenciação climática) segundo AIZZINI submeteram a vegetação a ampla diversificação macro e micro climática, desencadeando um ciclo de diferenciaçāo, em contraste com a fase de generalização da período Cretáceo-Eoceno anterior. A vegetaçẫo mesófila e malacofila foi forçada ao xeromorfismo e xerofitismo conforme a disponibilidade de água, fase em que constituiram-se os campos limpos e desencadearam-șe lentamente os processos de composição da floresta atiântica.

Recuos e avanços da vegetação aberta sobre a fechada prologaram-se durante todo Quaternário, adentrando o Holoceno com menor intensidade, alternando-se entre periodos de pedimentaçăo e dissecaçăo, acentuando o processo de diversificaçäo das espécies vegetais. Na atualidade conforme 
registrado por ASSIS(1985), ainda verifica-se tal processo no semi-árido brasileiro a exemplo da ocorrẻncia de refúgios de vegetação ombrófila própria de ambientes tropicais úmidos.

\section{FATORES GEOMORFOLÓGICOS AMBIENTAIS E A COBERTURA VEGETAL PRIMITIVA.}

MAACK, (1948:165) figura como um dos precursores do estudo das variaçōes climáticas e suas implicaçōes no revestimento floristico no Paraná, ao mencionar que os campos no Paraná, (Campos cerrados de Sengés, Campo do Mourăo, etc.) constituem relíquas de um clima passado mais seco, sendo que as florestas, com espécies próprias de clima mais úmido, progressivamente conquistaram terreno aos mesmos, encontrando-se atualmente os primeiros restritos às áreas de solos com menor fertilidade.

Estudando sedimentos detríticos continentais elaborados nas épocas de pedimentação e suas relaçōes com nivel marinho. BIGARELLA: AB'SABER, (1963)3, ANDRADE et al, (1963) concluem, terem sido semi-áridas no Brasit e Uruguai as épocas correspondentes as glaciaçóes pleistocênicas. Nestas épocas, as regiöes afastadas das áreas de acumulaçāo de gelo, erarn além de mais trias. também de clima mais rigorosamente semi-árido, fase em que ocorreu a retração das florestas e instalaram-se processos erosivos de degradaçāo lateral da paisagem. Os inter-glaciais, por seu turno eram mais quentes e úmidos, fase de expansẫo das florestas, intemperismo profundo $\Theta$ estabilizaçăo da pedogênese $€$ dissecaçăo linear do relevo.

Segundo BIGARELLA, (1964), camadas sedimentares em vários locais no Sul do Brasil documentam mudanças ciclicas e profundas durante o Quaternário. Com base no estudo destes depósitos e nos aspectos florísticos regionais descritos por KLEIN; HATSCHBACH, (1962), Bigarella, sugere modificaçóes climáticas relativamente recentes; onde condiçōes paleoctimáticas variáveis, vigorantes no Quaternário, foram responsáveis por respectivos avanços e recuos das florestas de acordo com a vigência de fases pluviais ou semi-áridas. Conforme o mesmo autor, a situação florestal atual teve sua expansăo e desenvolvimento subsequente a última fase seca que precedeu a formaçāo das várzeas atuais, cuja transiçăo de fase seca para úmida foi localmente datada pelo

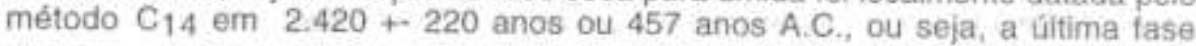
expansiva das florestas sobre os campos deu-se a cerca de 2400 anos.

Nos inter-glaciais as áreas semi-áridas e desérticas diminuiam, ilinandose em locais onde ainda nos períodos úmidos permaneciam condiçōes climáticas rigorosas. Nas épocas glaciais os núcleos de semi-aridez ou aridez tinham notável expansăo, transtormando em desertos consideráveis regióes geográficas, ocupadas por florestas nos inter-glaciais. BIGARELLA, (1964).

Ainda segundo o mesmo autor, dentro das épocas ùmidas e quentes, verificam-se freqüentes flutuaçōes climáticas, quando fases secas mais rigorosas alternaram-se com fases ûmidas. Eram estas variaçōes ciclicas menores. responsáveis por mudanças no revestimento florístico importando em expansōes

'BIGARELLA J,J.e Ab'SABER A.N. Aspectos paleogeográfícos c polecolimáticos de Cenozóico no Brasil Meridional-Inédito (1963) in BIGAREL_LA(1964) 
e retraçōes das florestas a partir dos núcleos de refúgio. Embora aparentemente as condiçóes das fases secas nāo fossem de rigor extremo, como das épocas de semi-aridez, elas eram contudo, suficientes para a expansằo das áreas de campo ou as ilhas de cerrado por sobre áreas normalmente ocupadas pelas florestas nas fases úmidas. Portanto um movimento ciclico de expansāo e retração das florestas deve ter ocorrido no passado recente, indicado por evidências geológicas.

Para TRICART, (1977), " na maioria đas regiōes as oscilaçōes climáticas foram suficientes para engrenar modificaçōes fisionômicas da cobertura vegetal, que influenciaram, a seu turno, os sistemas morfogenéticos conforme atestam as formaçōes superficiais e sucessōes, muito difundidas nos terraços climáticos. Nesse tipo de meio as condiçôes ecológicas atuais reinam a partir do último periodo frio, aproximadamente do início do Holoceno, grosseiramente há uns 10.000 anos."

BAOWN-Jf.; Ab'SÁBER, (1979), correlacionam as variaçōes climáticas do passado com a atual distribuiçăo de áreas endêmicas na América do Sul. Com base em informaçōes obtidas da integração de dados paleoclimáticos, geológicos, geomortológicos, pedológicos e palinológicos, os autores definiram a localizaçăo de antigos refúgios florestais, mapearam e estabeleceram sua relaçōes com a atual distribuição da cobertura vegetal.

Segundo a análise plena (geológica, geomorfológica e pedológica), da toposseqũencia, permite "compreender pari pasu, as mudanças ocorridas nos ecossistemas" tal fato, deve-se a possibilidade do reconhecimento de antigas superficies, de estruturas e depósitos correlativos ou ainda paleossolos relacionados a variaçōes das condições ambientais(oscilaçōes paleo-climáticas). permitindo interpretar sua dinămica espacial e temporal.

HACK, J. T.; GOODLETT, J.C, (1960); SWANSON; JAMES, (1977); STABLEIN, (1984) demostram as conexōes "Geoecológicas" florestais com processos "Geomorfodinámicos", fenómenos geomorfológicos e substrato geológico em áreas motanhosas.

SWANSON e JAMES, (1977), destacam particularmente a forte correlação entre instabilidade geomorfológica, topografia, geologia e tipo de cobertura vegetal, como condicionantes de processos geomorfológicos conhecidos como movimentos de massa, e suas significativas relaçöes com o desenvolvimento e a produçăo florestal em áreas montanhosas.

PICKUP: CHEWINGS (1996) demonstram a correlaçāo entre as condiçōes da hidrologia superficial e processos erosivos com os indices cobertura vegetal e topográficos, os quais combinados ou de forma individualizada como a do modelo topográfico-vegetacional definido pelos autores. E em funçăo da elevada correlação encontrada, indicam que tais modelos podem ser utilizados com sucesso, para compreensão da distribuição espacial de processos erosionais e deposicionais ou da dinámica hidrológica, sendo portanto indicadores de redistribuição da umidade e perda de solos ou sua acumulaçāo na paisagem.

Pesquisas de caráter interdisciplinar de paleoambientes (ecossistemas), envolvendo os campos da biologia e das geociências, como as contribuiçōes de MULLER (1970), HAFFER (1969), VAZOLINI (1970), AVILA-PIRES (1974), BIGARELLA; ANDRADE-LIMA; RIEHS, (1975), onde particularmente os últimos 
autores apresentam proposta metodológica integrando estudos geológicos, geomorfológicos, paleoclimáticos, biogeográficos e genéticos; esses autores destacam a importāncia do estudo das relaçōes entre a vegetação e o relevo e de sua dinâmica ao longo do Quaternário do Brasil tropical e subtropical, para a reconstituiçăo paleoambiental, pois concluem que os ambientes sucederam-se a ciclos geo-climáticos.

Para BIGARELLA; ANDRADE-LIMA; RIEHS, (1975), existem fortes indícios de que "a destruiçăo da vegetação vem acompanhada de taxa elevada de erosão seguida da degradação ambiental ... cessadas as condiçōes adversas, o ambiente recupera, no tempo e no espaço, suas condiçōes anteriores com desenvolvimento acentuado da pedogênese extensiva."

Portanto, mesmo sendo a grande maioria das pesquisas desenvolvidas com base em análises parciais das relaçōes entre as características fitogeomorfológicas da paisagem, nas referências apresentadas dentre inúmeras existentes, observa-se sua importância e necessidade da busca e aperfeiçoamento de metodologia interdisciplinar para maior aproveitamento do conhecimento fitogeomorfológico, mesmo em levantamentos temáticos especificos, como os mapeamentos de: solos, geomortologia, fitogeografia, uso da terra, etc.

A seguir, em caráter informativo săo apresentadas algumas contribuiçōes da geomorfologia que podem servir ao propósito da fitogeomorfologia aplicada na análise da paisagem de uma forma mais abrangente. Na seleçāo, citam-se alguns modelos dentre diversos existentes, que mereceriam detalhada revisăo bibliográfica e discussăo na tentativa de aproximaçāo e construção de um modelo de análise global, o que deverá ser tarefa árdua por envolver, além de inùmeros livros $\theta$ um número bastante significativo de publicaçōes periódicas, e conciliar ainda as discordâncias das próprias teorias que tratam da origem e evolução das paisagens.

\section{MODELOS GEOMORFOLÓGICOS E CLASSIFICAÇĀO FITOGEOGRÁFICA DA PAISAGEM.}

A paisagem em sua totalidade, na concepçāo geográfica adotada na presente análise, é definida como resultante da interaçâo de elementos físicos, biológicos e mais recentemente modificada pelas açōes antrópicas, cujo produto apresenta caracteristicas particulares, em constante evoluçăo espaço-temporal. O estudo da organizaçăo espacial de seus elementos e de suas unidades integradas, na classificação da paisagem, tem utilizado a compartimentaçấo geomorfológica como um dos principais critérios de mapeamento.

A combinaçăo de fatores geoecológicos (bióticos e abióticos), principalmente de natureza climática, conduziram a condiçōes ambientais com variabilidade por vezes bastante sutís no desenvolvimento de maior ou menor diversidade de nichos ecológicos e de habitats, que influenciaram por sua vez diretamente na diversidade, estrutura e dinămica da flora e fauna e de seu biótopo atual.

O biótopo delimitado, classificado e caracterizado como um todo homogêneo deve passar portanto, por uma análise mais detalhada, a qual pode ser tomada pelo estudo integrado (geossistémico) dos diferentes topos segundo TROPPMAIR, (1987): 
Morfotopo- tipos de formas geomorfológicas, com propriedades próprias e definidas, associados ao mesmo processo morfogenético.

Pedotopo- complexo parcial do solo com propriedades físicas, químicas e biológicas especificas.

Hidrotopo- complexo parcial que se caracteriza pela mesma superfíciede água ou o mesmo comportarnento da àgua do solo. relevo (morfotopo).

Climatopo: clima local (mesoclima) associado principalmente ao

Fitotopo- abrange a cobertura vegetal, sua composição, dinâmica (sucessăo) e expressăo como reflexo das condiçōes geoecologicas reinantes, portanto estreitamente ligado ao pedotopo, hidrotopo e climatopo.

Zootopo- abrange a fauna local, sua dinâmica, seu hábitat, sua adaptação às condiçōes ecológicas decorrentes dos demais topos.

Portanto os principais componentes geomorfológicos; material de origem ou "parental", a morfologia do terreno e processos que resultam da interaçấo destes componentes com o clima, solos e organismos vivos é que determinam o grau de influência e importância geoecológica dos fenômenos geodinâmicos, e da evoluçăo da morfologia do relevo, na formaçăo dos solos e consequentemente na distribuiçăo da cobertura vegetal e sua evoluçăo, facilitam através de sua análise a compreensăo da atual distribuiçăo florestal assim como a do passado.

TRICART(1977), em sua proposta de "classificação ecodinâmica dos meios ambientes," destaca a importảncia da interaçăo entre os fatores geomorfológicos, solos e clima na estabilidade ambiental atual. O autor destaca na mesma obra, o papel das oscilaçōes climáticas quatemárias nas mudanças fisionômicas. da cobertura vegetal, que infuenciaram os sistemas morfogenéticos, salientando o função da floresta na "fitoestablização" dos ambientes atualmente considerados estáveis, assim como a funçăo das áreas de longa estabilidade "geodinâmica" como condiçāo para a "fitoestasia", termo análogo ao "bioestasia" proposto por ERHART(1955). Em função da intensidade dos processos atuais TRICART(1977). sugere ainda a classificaçäo ecodinâmica dos meios ambientes no nivel taxonô. mico mais elevado em: meios estáveis, meios intergrades e os meios fortemente instáveis.

DALRYMPLE et al (1968), idealizaram um modelo funcional para subdivisão das vertentes denominado de "nine-unit landsurface model", onde as diversas unidades morfológicas que compōem as encostas dos vales, sāo caracterizadas por diferentes sistemas processos-resposta de natureza pedogeomorfológica contemporánea, assim como, em inúmeros outros modelos propostos como: HACK; GOODLETT, (1960), para delimitar unidades geomorfológicas simples. Nesses modelos sảo mais ou menos evidenciadas as referidas relaçōes entre relevo e propriedades dos solos, as quais săo identificadas com a distribuição da vegetaçảo, a qual realça, destaca e facilita o mapeamento de seus componentes abióticos e de sua dinámica.

HOWARD,(1991); HOWARD; MITCHELL, (1980) propőem a subdivisấo regional da paisagem em unidades Tand units", para estudos florestais, com base em critérios de hieraquizaçăo geomorfológica da mesma, onde a análise fitogeomorfológica é utilizada na classificaçáo de unidades da terra: "land system, land catena, land facet e land element ". Sendo que a vegetaçăo tem maior peso na delimitaçāo das duas ùltimas unidades menores e a geomorfologia, nos sistemas e catenas.

O referido modelo de classificação da terra ou unidades de paisagem, reforça a tese de que a distribuição das unidades de paisagem atuais, ou do 
passado, podem ser melhor compreendidas e delimitadas, mediante a individualização de unidades fitogeomorfológicas.

PASSOS; COSTA (inédito), através de análise fitogeomorfológica para inúmeras feiçőes morfológicas registradas nas várzeas do plaino aluvial do rio Iguaçu na regiăo metropolitana de Curitiba-Pr., idetificaram relaçóes entre o tipo de cobertura vegetal com feiçōes morfológicas, em funçāo da natureza dos materiais constituintes e suas características de drenagem e nivel freático, os quais decorrem da dinâmica fluvial e evoluçāo das encostas. (Fig.03).

Portanto, sob o aspecto ambiental, a influência geomorfológica na mudança da qualidade fisico-quimica e hidrodinâmica do sitio, (Fig.04) pode ser associada a fisionomia e fenologia da cobertura vegetal, a variaçōes abruptas na cobertura, ou ainda a presença de outros bioindicadores, que podem ou não estar relacionados a variaçŏes topográficas, mas seguramente acusam diferenças nos processos morfogenéticos presentes ou decorrem de caracteristicas herdadas por produtos de sua ação passada, as quais podem ser destacadas ou amenizadas pela pedogênese ao longo do tempo.

Fig.03. Perfil esquemático, de seção típica do leito maior ou excepcional até o canal principal do rio Iguaçu, nas proximidades de Curitiba. Relaçöes com a cobertura vegetal, sendo a Mata Ciliar associada a faixa de dominio dos canais meândricos (1), meandros abandonados (4), barras e diques marginais com depósitos arenosos (2); ainda no domínio dos depósitos aluviais Holocênicos (6). sob os depósitos siltico argilosos e orgânicos (3), da planicie de inundaçāo sazonal ocorrem os Campos Edáficos, que estendern-se sobre os leques colưvio aluviais recentes (5); no segmento mais elevado sobre antigos terraços fluviais (7), leques colúvio aluviais (5), estabelecendo a transiçăo entre a vegetação de várzea e a Mata de Araucaria, a qual encontra o seu pleno desenvolvimento sobre a as baixas rampas de colúvio (8), e elúvios do embasamento cristalino(9). recobertos por solos coluviais mais ou menos desenvolvidos.

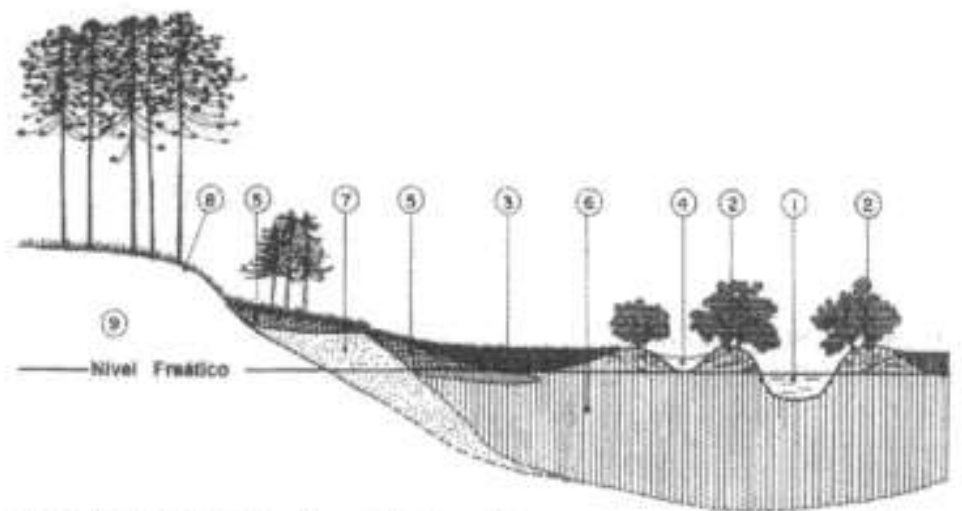

Fig.04. Exemplo da relação fitogeomorfológica de seção típica da vegetaçăo no municipio de Guaratuba- Pr. Adap. BIGARELLA (1978) com base em dados de VELOSO; KLEIN (1961). 


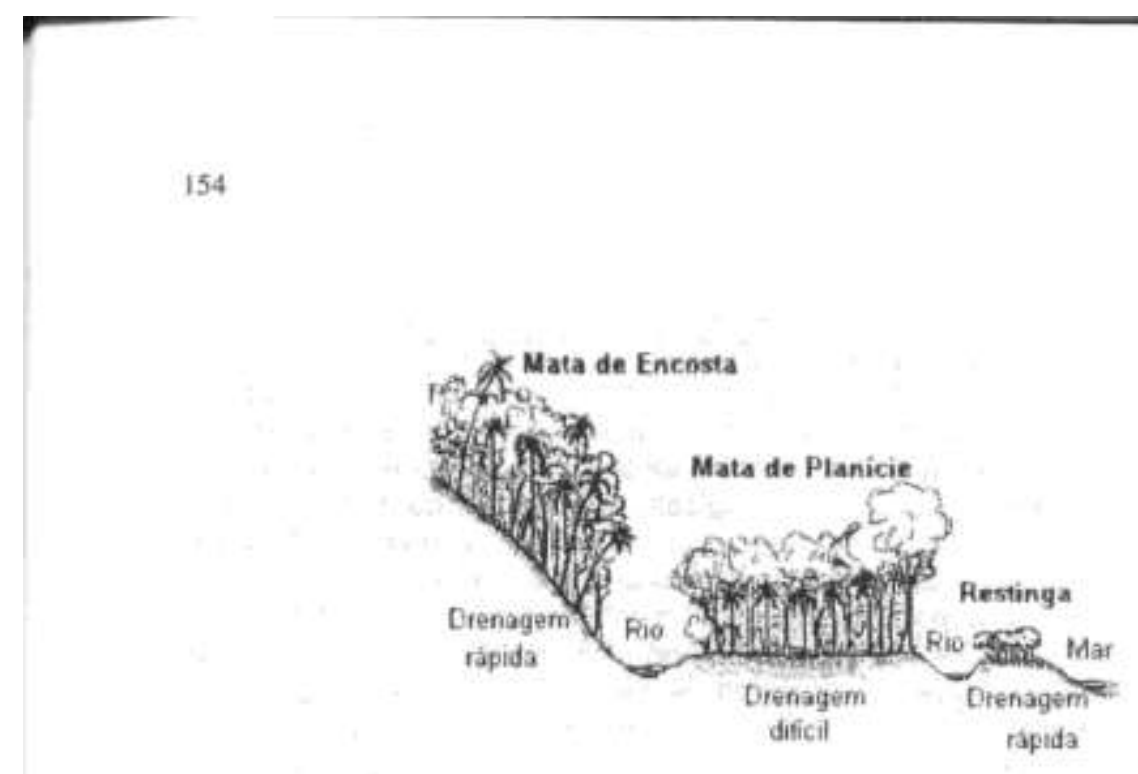




\section{CONSIDERAÇÕES FINAIS}

A distribuiçăo atual das biocenoses e sua biodiversidade, particularmente destacado na vegetaçăo, em grande parte, é resultante da evoluçăo de processos sucessionais, desencadeados como resposta a aiteraçōes ambientais desencadeadas ao longo do tempo geológico, sendo nescessário para seu entendimento, o conhecimento, análise e avaliaçāo, da atuação passada de fatores do meio físico, relacionados a modificaçōes ecológicas, que suscederamse há milhares de anos, e particularmente implicaram em alteraçōes da cobertura vegetal, decorrentes de mudanças climáticas e geomorfológicas.

Portanto, o estudo fitogeomorfológico, apresenta um vasto campo de aplicação a ser explorado, e aperfeiçoado, pois além de facilitar a compreensăo da origem, evoluçăo, divisāo e correlaçăo de componentes da paisagem, facilita ainda a avaliaçăo com maior abrangência de impactos produzidos por fenómenos naturais ou açōes antrópicas no meio amblente, assim como, determinar seu potencial de utilizaçăo.

Cabe resaltar ainda, que o uso de modelos integrando diversas informaçōes temáticas, mesmo que aperfeiçoado, obriga forçosamente a sintetizaçāo, e consequientemente nẩo substituem os estudos e levantamentos sistemáticos dos diversos conhecimentos específicos envolvidos, onde efetivamente săo desenvolvidas novas formas de pesquisa $\theta$ produzidas as bases de informaçấo para os estudos interdisciplinares integrados.

Finalmente, deve-se destacar que os atuais avanços da informática, de técnicas de sensoriamento remoto e de sistemas de informaçōes geográficas, mediante o desenvolvimento de equipamentos e softwares, especificos para o geoprocessamento (processamento digital de imagens e sistemas de informação geografica - SIG.), apresentam novas perspectivas de facilidades tecnológicas, que poderăo dar um grande auxilio aos estudos fitogeomorfológicos, na aquisiçăo de dados $e$ avaliaçăo de novas informaçōes e mediante o georeferenciamento de dados existentes facilitar seu gerenciamento e análise. como por exemple o uso integrado de SIG e aplicaçōes de sensoriamento remoto em modelos digitais do terreno.

\section{BIBLIOGRAFIA}

Ab'SABER,A.N. Províncias geológicas e domínios morfoclimáticos no Brasil. USP. Instituto de GeogrGeomorfologia 20:1-26p., 1970.

ANDRADE, G.O., BIGARELLA, J.J. e LINS, R.G. Contribuiçăo à geomorfologia e paleoclimatologia do Rio Grande do Sul e Uruguai. Boletim Paranaense de geografia $\mathrm{N}^{\mathrm{OS}} 8$ e 9, Curitiba. 123-131p, 1963.

\section{AVILA-PIRES F.D. de. Caracterizaçäo Zoogeográfica da Província}

Amazônica . I ,II. An. Acad. Brasil. Ciênc. 46(1): 133-158/159-181, 1974. 
BERTRAND, G. Paisagem e geografia física global- esbôço metodológico. Caderno de ciências da terra v.13. USP-Instituto de Geografia, São Paulo, 1972. 27p

BIGARELLA, J.J. Variaçōes climáticas no quaternário e suas implicaçōes no revestimento florístico do Paraná. Boletim Paranaense de Geografia $\mathrm{N}^{\mathrm{OS}} 10$ a 15, Curitiba-Pr., 1964, 211-231p.

BIGARELLA, J.J. A Serra do Mar e a porçầo oriental do estado do Paraná . (Um problema de segurança ambiental e nacional/ contibuiçâo à geografia, geologia e ecologia regional.). Gov. Estado do Paraná/ADEA. Curitiba, 1978. 248p

BIGARELLA J.J. e MAZUCHOWSKI. Visāo integrada da problemática da erosāo - Livro Guia. $3^{2}$ Simpósio Nacional de Controle de erosāo. ABGE/ADEA, Maringá-Pr., 1985, 332p.

BIGARELLA J.J; ANDRADE-LIMA D. de; RIEHS, P.J. Cosiderações a respeito das mudanças paleoambientais na distribuiçōa de algumas espécies vegetais e animais no Brasil. An. Acad. Brasil. Ciênc. 47(Suplemento): 411-464, 1975.

BAOWN-Jr., K.S.. e AB'SABER. Ice-age Florest Refuges and Evolution in Neotropics: Correlation of paleoclimatological, geomorphological and pedological data with modern biological endemism. Paleoclimas v.5. USP. Instituto de Geografia, Säo Paulo, 1979. 30p.

DALRYMPLE, J.B., BLONG, R.J. e CONACHER, A.J. A hypothetical nine unit landsurface model. Zeitschrit für Geomorphologie, 12, 60-70,1968.

De PLOEY, J; CRUZ, O. Landslides in the Sierro do Mar, Brazil. CATENA 6, 2. $111-122,1979$.

DOUGLAS, I. Man vegetation and the sediment yield of rivers. Nature 215 925-928, 1967.

DUNNE, Th. Sediment yield and land use in tropical catchments. J, Hydrol. 42. $281-300,1979$. 
ERHART, $H$. Biostasie et rhesistasie esquime dúne théorie sur le rôle de la pedogenése en tant phenoméne geologique. C.R.Acad.Sci.,241: $1218-1220,1955$.

HACK, J.T. e GOODLETT, J.C. Geomorphology and florest ecology of a mountain region in the central Appalachians. U.S. Geological Survey. Porfessional paper -347.U.S.Print, Off., Waschington, 1960, 66p.

HAFFER, J. Speciation in Amazonian forest birds. Science, 165: 131-137, 1969.

HOWARD, J.A. Multi-band concepts of florested land units. International Symposium of Photo-Interpretation, Vol.1, International Archives of Fotogrametry. Desdren, 1970.

HOWARD, J.A. Remote sensing of florest resourses- Theory and aplication. Chapman \& Hall. London, 1991. p. 243.

HOWARD, J. A, e MITCHELL. Phyto-geomorphyc classification of the landscape. Geotorum, 11. 85-106, 1980.

KLEIN R.M.; HATSCHBACH G. Fisionomia e notas sobre a vegetação para acompanhar a planta fitogeográfica do minicipio de Curitiba e arredores Bol. Da Universidade do Paraná - Instit. de Geologia / Geografia Fisica $n^{2} 4,30 p$. dezembro, 1962.

LACOSTE, A. e SALANON, R. Biogeografia. $1^{2} \mathrm{ed}$ Barcelona: OIKOS-TAU. 1973.p.91,135,175-179.

MAACK, R. Notas preliminares sobre o clima,solo e Vegetação no estado do Paraná. Arq. Biol. Tecn. 3: 103-200, 1948,

MÛLLER,P. Vertbratenfaunen brasilianischer Inseln as indicatioren für glaziale und postglaziale vegetacionfluktuactionen. Verhd. Deusches Zool. Ges.Würzburg.

PASSOS E. COSTA T.M. (Inédito) Recursos naturais das várzeas de Curitiba. COMEC. 
PICKUP G.; CHEWINGS V.H. Correlations between DEM- derived topographic indices and Remotely-sensed vegetation cover in Rangerlands. Earth Surface Processes and Landforms - The journal of the British geomorphological resach group, Wiley.Vol.21, 517-529 (1996).

REMEZOV N.P. e POGREBNYAK P.S. Florest soil science. Trad. A. Gourevitch. IPST., Jerusalêm, 1969. 261p.

RIZZINI, C.T. Tratado de Fitigeografia do Brasil. .Hucitec-Edusp. Săo Paulo. V.2, 374p., 1979.

ROHDERBURG,H. Beitrăge zur allgemeinen Geomorphologie der Tropen und Sbtropen; Geomorphodynamik un vegetation Klimazyklische Sedimentation- Panplain/Pediplain- Pediment- Terrassentreppen. CATENA 10, 4. 393-438, 1983.

SEMMEL, A. ROHDENBURG, $\mathrm{H}$. Untersuchungen zur Bode und Reliefentwicklung in Sûd-Brasilien. CATENA 6, 2. 203-207, 1979.

SWANSON, F.J.; JAMES, M.E. Geology and geomorphology of the Experimental Florest, Western Cascades, Oregon. U.S.D.A. For. Serv. Pac. Norwest. For. Range Exp. Stn, Portland, Oregon PNW-188, 1977.

STABLEIN, G. Geomorphic altitudinal zonation in the Artic-alpine mountaisns of Greenland. Moutain Research and Development, . 4, 319-31, 1984.

TRICART, J. Ecodinâmica . SUPREM/IBGE, Rio de Janeiro, 1977. $97 \mathrm{p}$.

TROPPMAIR, H. Biogeografia e meio Ambiente. Graff Set, Rio Claro, 1987. $275 p$.

VANZOLINI, P.E, Zoologia sistemática, geografia e a origem das espécies. Univ. S. Paulo, Inst. Geogr. Série Teses e Monografias, 3: 1-56, 1970.

VELOSO, H.P.; KLEIN. R.M. As cominidades e associaçōes vegetais da mata pluvial do sul do Brasil. III As associaçōes das planícies costeiras do Quaternáriio, situadas entre o rio Itapocu (Estado de Santa Catarina) e a Baía de Paranaguá (Estado do Paraná). Sellowia, 13(13): 205-260, 1961. 